\title{
Interpersonal Moderators of the Effects of Upward Comparisons on Ability Judgments
}

\author{
Kenneth D. Locke \\ University of Idaho
}

\begin{abstract}
In everyday life, the meaning - and thus the consequences - of social comparisons are shaped by the interpersonal relationship with the comparison target. In two studies, undergraduates described 1,863 naturally occurring upward social comparisons. Participants ascribed higher ability levels to themselves when they had an ongoing competition or close (but not extremely close) relationship with the upward comparison target. Participants ascribed lower ability levels to distant and disliked targets (especially when their standing relative to a disliked target was personally important). Thus, perceived differences between the abilities of the self and the target were minimized when the target was disliked, moderately close, or a rival. These findings extend and qualify findings from laboratory studies of how upward comparisons affect ability judgments.
\end{abstract}

An upward social comparison occurs when an individual notices how another person is superior to the self. Decades of research have demonstrated myriad positive and negative effects of upward comparisons (Brickman \& Bullman, 1977). For example, upward comparisons tend to enhance comparers' selfevaluations when they construe themselves as like or capable of becoming like the upward comparison target but tend to undermine comparers' self-evaluations when they construe themselves as unlike or incapable of becoming like the upward comparison target (Collins, 1996; Lockwood \& Kunda, 1997). As a result, upward comparisons are more likely to enhance self-evaluations when the comparison target is moderately rather than extremely superior to the self (Mussweiler, Ruter, \& Epstude, 2004).

Upward comparisons can also enhance or undermine performance. For example, comparing with a slightly superior performer while completing a task can be motivating and enhance performance (Seta, 1982), but comparing with a far superior performer while completing a task one is invested in can be upsetting and undermine performance (Seta, Seta, \& Donaldson, 1991). Likewise, research has found that students who

Correspondence should be sent to Kenneth D. Locke, Department of Psychology, University of Idaho, Moscow, ID, 83844. E-mail: klocke@uidaho.edu choose to compare with slightly more successful classmates show improvements in academic performance (Blanton, Buunk, Gibbons, \& Kuyper, 1999; Huguet, Dumas, Monteil, \& Genestoux, 2001; Seaton et al., 2008), whereas people tend to do worse on intelligence tests after being exposed to an extremely intellectually superior target (Dijksterhuis et al., 1998). The studies just reviewed highlight two points: First, upward comparisons can have important consequences, and second, those consequences are shaped in part by the comparers' inferences about the relative abilities of the self and the target.

\section{ELEVATING THE ABILITIES OF SELF AND OTHERS}

If moderately superior targets enhance self-evaluations and performances more reliably than do very superior targets, then people might be expected to moderate rather than exaggerate the superiority of people who outperform them. Yet people may sometimes have good reasons to elevate the ability of upward targets. Most people prefer to believe and do believe that they are "better than average" on most dimensions (Alicke \& Govorun, 2005). Being outperformed can challenge that belief. However, if people construe the upward target's ability as off-the-scale exceptional, then they can 
discount the relevance of that target's performance for scaling their own ability level. Even if they construe the target's ability level as very high but not off-thescale, they can still maintain that their own ability level, although inferior, is at least above average. Finally, by complimenting the ability of superior performers, comparers can protect their belief in being above average in a way that makes them appear - to either themselves or others - to be honest and magnanimous.

Research confirms that comparers do sometimes elevate the abilities of upward targets. Alicke, LoSchiavo, Zerbst, and Zhang (1997) had confederates outperform participants on a test of perceptual intelligence-a dimension on which people tend to believe they are better than average (Lassiter \& Munhall, 2001). The participants rated the confederate significantly higher in perceptual intelligence than did observers; thus, the participants seemed prepared to conclude that "the person who outperforms me is a genius" (Alicke et al., 1997, p. 781), leading the authors to dub this phenomenon "the genius effect." These findings have since been replicated (Lassiter \& Munhall, 2001). However, the genius effect may be specific to domains in which the comparer is confident that he or she is above average; for example, Lassiter, Clark, Munhall, and Lindberg (2008) found that when people were outperformed in a domain in which they considered themselves untalented, they made lower ratings of the target's abilities than did observers.

\section{RELATIONSHIP VARIABLES MODERATE ABILITY JUDGMENTS}

Much of the research on reactions to social comparisons - such as the research just described on the "genius effect"- has studied comparisons between strangers in laboratory settings. Such comparisons are not representative of the spontaneous comparisons people make in the course of their everyday lives (Locke \& Nekich, 2000). Of particular relevance to the current investigation is the finding that in at least two thirds of naturally occurring social comparisons the targets are known others, and most of these known targets are friends and relatives (Locke, 2003, 2007). Findings from studies of constrained comparisons with strangers may not always generalize to these more complicated comparisons with known targets - people with whom there are preexisting feelings and interdependencies - that populate everyday life.

The current article aims to extend previous research on upward comparisons with strangers in controlled settings by instead studying the upward comparisons that people spontaneously make with diverse targets in the course of their everyday lives. By definition, social comparisons involve positioning the self relative to a particular target person or persons. Because social comparisons are embedded in social relationships, they will be influenced by the social emotions and motives (such as intimacy and jealousy) that those relationships activate. The current studies will assess the influence of four interpersonal variables - namely, closeness, dislike, competition, and personalization-on judgments of the abilities of the self and the target following upward comparisons. In the following paragraphs, I explain how and why each of these relationship factors is likely to influence ability judgments.

One prominent model of social comparisons that incorporates relationship factors is the self-evaluation maintenance (SEM) model (Tesser, 1988). The model posits that upward comparisons are especially threatening to self-evaluations when the comparer considers the comparison target to be a close other and the performance in question to be personally relevant. Several studies of comparisons with friends versus strangers have supported the model (Tesser, 1988). The extended SEM model (Beach \& Tesser, 1993) subsequently posited that upward comparisons would be less distressing to intimate partners than friends because partners are more able to feel empathy with and pride in each other's success. In support of the extended SEM model, several studies have found that people have more positive or less negative reactions if they are outperformed by someone with whom they share an extremely close or "identity" relationship (Beach et al., 1998; McFarland, Buehler, \& MacKay, 2001; Pinkus, Lockwood, Schimmack, \& Fournier, 2008). Nonetheless, most of those studies suggest that it is still easier to enjoy a partner's superiority if the attribute being compared is not personally relevant; consequently, partners may stake their status on different performance domains to avoid uncomfortable rivalries (Beach \& Tesser, 1993). In sum, the SEM and extended SEM models suggest that people are most threatened by being inferior to a moderately close target - that is, someone with whom (unlike distant others) they will keep comparing themselves but from whom (unlike very close others) they will receive little reflected glory. Thus, my first hypothesis was as follows:

H1: Comparers will rank the abilities of the self and an upward target as more similar when the target is moderately close than when the target is either very close or not at all close.

Closeness is not the only relationship variable that is likely to influence ability judgments. A long tradition of theory and research suggests that evaluation (good-bad) is the most basic and automatic dimension of social cognition, and that ascribing both good and bad qualities to the same target creates an unpleasant and unstable state 
of incongruity or dissonance (Osgood, 1960). Consequently, people prefer to ascribe positive (rather than negative) attributes to liked others and negative (rather than positive) attributes to disliked others (Heider, 1958). For example, even if Joe got admitted to a better school than Bob, if Bob detests Joe then he may refuse to believe that Joe's abilities greatly exceed his own and those of other applicants. Thus, my second hypothesis was as follows:

$\mathrm{H} 2$ : Comparers will be less likely to ascribe high levels of ability to disliked comparison targets than to liked comparison targets.

A third interpersonal variable that seems likely to influence reactions to being outperformed is having an ongoing competition with the target. Whether or not competitors like their rivals, they still want to win, and deeming their rivals vastly superior to the self implies that the self will keep losing. For instance, imagine Sue just won a triathlon. If another competitor, Jane, thinks "Sue is unbeatable," that may help Jane feel better about losing, but it will not help Jane feel more confident about beating Sue in the next race. Thus, my third hypothesis was as follows:

H3: Comparers will rank the abilities of the self and an upward target as more similar when they have a rivalry with the target.

The fourth potential moderator is technically a property of the comparison rather than a property of the relationship with the target. Studies of naturally occurring social comparisons have shown that more than two thirds of comparisons are personalized comparisons in which the comparer's main concern is "How do I compare particularly with this one person" rather than "How do I compare with others in general" (Locke, 2007). Personalized comparisons occur more often when the comparer feels close to or strongly about the target and when the target's attribute is distinctive, presumably because these conditions prompt the comparer to focus on the target as a distinct individual (Locke, 2007). Alicke et al. (1997) proposed that "exaggerating the outperformer's ability is a construal mechanism that negates the potentially negative implications of unfavorable social comparisons by allowing inferior performers to discount the relevance of the comparison" (p. 782). If the comparison is personalized, though, then one's standing relative to the target is of intrinsic importance, regardless of whether it is informative of one's standing relative to others in general. For example, if $\mathrm{Al}$ outperforms Rick on a test and Rick's concern is how he compares with a typical student, then thinking " $\mathrm{Al}$ is a genius"-and therefore an irrelevant standard-may be encouraging. However, if all Rick cares about is how he ranks relative to $\mathrm{Al}$, then thinking " $\mathrm{Al}$ is a genius" could be undermining instead. Thus, my fourth hypothesis was as follows:

H4: Comparers will rank the abilities of the self and an upward target as more similar to the extent that they personalize the comparison.

My fifth and final hypothesis concerned the effect of the perceived abilities of the target on the emotional consequences of an upward comparison. One explanation of why people might elevate the abilities of an outperformer is that doing so helps them to feel better about being outperformed. However, previous research on perceptions of target abilities following upward comparisons has not assessed how those perceptions affect feelings about being outperformed. Therefore, in the current studies I asked comparers how they felt about being outperformed, and my hypothesis was as follows:

H5: The greater the perceived abilities of an upward target, the better comparers will feel about the target outperforming them.

\section{OVERVIEW OF THE STUDIES}

To test these hypotheses I conducted two studies in which participants described upward comparisons they had made spontaneously in the course of their everyday activities. I studied naturally occurring social comparisons because I needed data on comparisons with a diversity of targets, including those that are difficult to study in controlled conditions (e.g., comparisons with targets who are well known but disliked). The key outcome variables in both studies were emotions and judgments of the relevant abilities of the self and the target; participants also made ratings of closeness and rivalry (in Study 1), personalization (in Study 2), and liking (in both studies).

\section{STUDY 1}

To gather data on naturally occurring social comparisons, I employed an event-contingent self-recording procedure that has been used in numerous social comparison studies (e.g., Locke, 2003; Wheeler \& Miyake, 1992). Specifically, each time participants noticed themselves making an upward social comparison they completed an "Upward Comparison Record" that assessed relationship variables (i.e., liking, rivalry, and closeness), the perceived abilities of the self and the target in the domain being compared, and the affect evoked by the comparison. I hypothesized that comparers would (a) ascribe disliked targets lower ability levels (H2), (b) ascribe the self and the target similar abilities if the target was a rival or moderately close 
other ( $\mathrm{H} 1$ and $\mathrm{H} 3)$, and (c) feel better about being outperformed by targets to whom they ascribed greater abilities (H5).

\section{Method}

Participants. University of Idaho undergraduates (76 female, 55 male; age range $=18-49$ years, $M=20.1$, $S D=4.3)$ participated for extra credit in psychology classes. The participants described their ethnicity as follows: $90.8 \%$ European American; 3.8\% Latino; $3.1 \%$ Asian American, Native-American, or African American; 2.3\% "Other."

Materials. The upward comparison records assessed the following information. First, participants indicated their closeness with the comparison target on the following 5-point scale: -2 (not close or important (e.g., stranger)), -1 (slightly close or important (e.g., acquaintance or distant relative)), 0 (moderately close or important (e.g., ordinary friend or coworker you see regularly)), +1 (very close or important (e.g., a close friend or close relative)), and +2 (extremely close or important (e.g., a spouse or long-term romantic partner)). Second, the participants wrote on a blank line "specifically how the other person was superior." Third, the participants responded to five items on scales ranging 0 (not at all) to 9 (very much). Two items assessed target dislike ("I typically have negative feelings toward this person," "I typically have positive feelings toward this person" [reverse scored]; Cronbach's $\alpha=.63$ ). One item assessed rivalry ("I feel competition or rivalry with this person in this domain"). Two items assessed overall feelings ("When I think about the other person's performance or outcome I feel positive feelings" and "When I think about the other person's performance or outcome I feel negative feelings" [reverse scored]; $\alpha=.73)$. Finally, participants rated, "How would your rank your abilities in this domain?" and "How would you rank the other person's abilities in this domain?" on scales ranging 0 (extremely low) to 9 (extremely high). (The latter item was the outcome measure in Alicke et al., 1997.)

Procedure. Self-explanatory packets containing 10 upward comparison records and detailed instructions were distributed in classrooms. The instructions stated,

An upward social comparison is when you notice that someone has done better than you or outperformed you in some way. ... Whenever you make an upward social comparison... please complete one of the attached "Upward Comparison Record" sheets. ... Some of you may notice 10 upward comparisons and complete all 10 record sheets in a single day. Others may take a couple of weeks to notice and describe 10 upward comparisons. The important thing is that you...complete an "Upward Comparison Record" each time you make an upward comparison, whether that occurs twice a week or ten times a day.

After completing all 10 record sheets, participants returned the packet either by bringing it to our laboratory or by campus mail.

\section{Results and Discussion}

Data analysis. Because the data were observations from multiple comparison records nested within participants, I used multilevel modeling (Luke, 2004) to analyze the data. There were potentially 1,310 observations (131 participants $\times 10$ records) for each variable. For every record variable except closeness, fewer than 12 (i.e., $<1 \%$ ) of the 1,310 observations were missing. Perhaps because of its location at the top of the comparison record, $93(7.1 \%)$ of the potential observations for closeness were missing.

Descriptive statistics. Two coders independently coded participants' open-ended descriptions of "how the other person was superior" into six categories (Cohen's $\kappa=.69$, indicating substantial agreement; Landis \& Koch, 1977) and resolved disagreements by discussion, yielding the following percentages in each category: (a) 54\% compared a specific outcome of a test, game, or other easily ranked competition (e.g., "better grade on STAT 251 quiz," "lifted more at the gym," "beat me in poker"); (b) $24 \%$ compared a general skill (e.g., "better at math," "more organized"); (c) 7\% compared social or romantic success (e.g., "got asked out by a cute boy," "more popular"); (d) 7\% involved positions, awards, or recognition (e.g., "got the intern job I wanted," "got into National Honor society"); (e) 6\% compared external or material attributes such as wealth and looks (e.g., "better physique," "had a newer version of my car"); and (f) $2 \%$ were illegible or did not fit into any of the categories (e.g., "has better looking future").

Participants described the closeness of the comparison target as follows: $11.9 \%$ were not close (e.g., stranger), $12.4 \%$ were slightly close (e.g., acquaintance), $33.4 \%$ were moderately close (e.g., friend), $32.2 \%$ were very close (e.g., close friend), and $10.0 \%$ were extremely close (e.g., spouse). Thus, two thirds of comparisons were with moderately or very close others.

I estimated the means for the continuous variables by fitting the following multilevel model:

$$
\mathrm{Y}_{\mathrm{ij}}=\gamma_{00}+u_{0 \mathrm{j}}+r_{\mathrm{ij}}
$$


TABLE 1

Descriptive Statistics (Study 1)

\begin{tabular}{lcc}
\hline Measure & $\gamma_{00}$ & $S E$ \\
\hline Dislike & 2.03 & 0.08 \\
Rivalry & 4.73 & 0.16 \\
Feelings & 5.42 & 0.13 \\
Target's Ability & 6.97 & 0.09 \\
Own Ability & 5.87 & 0.09 \\
\hline
\end{tabular}

Note. Ratings were made on 0 -to-9 scales.

For example, if $\mathrm{Y}$ is the rating of the target's ability, then $\mathrm{Y}_{\mathrm{ij}}$ is the ability rating on participant $j$ 's $i$ th comparison, $\gamma_{00}$ is the ability rating grand mean, and $u_{0 j}$ and $r_{i j}$ are the residuals unique to participant $j$ and comparison $i$, respectively. Table 1 shows the mean $\left(\gamma_{00}\right)$ for each variable. The midpoint of the rating scales was 4.5. Dislike of the target was infrequent. Rivalry was more common. Feelings tended to be above the scale midpoint. Comparers typically ranked the target's abilities in the comparison domain as superior to those of the self but still rated the self's abilities as high.

Effects of relationship factors. To test if withinsubjects variations in the relationship with the target explained within-subjects variations in ability rankings, I expanded Equation 1 as follows:

$$
\mathrm{Y}_{\mathrm{ij}}=\gamma_{00}+\gamma_{10} \mathrm{X}_{\mathrm{ij}}+u_{0 \mathrm{j}}+u_{\mathrm{ij}} \mathrm{X}_{\mathrm{ij}}+r_{\mathrm{ij}} .
$$

For example, if $Y_{\mathrm{ij}}$ is the rating of the target's ability and $\mathrm{X}_{\mathrm{ij}}$ is the rating of rivalry with that target on participant $j$ 's $i$ th comparison, then $\gamma_{10}$ is the mean rivalry-ability slope grand mean and $u_{1 \mathrm{j}}$ is the slope component unique to $j$. All variables were standardized to facilitate interpretation.

Table 2 shows the effects of the relationship with the comparison target on ratings of the abilities of the

TABLE 2

Ability Rankings as a Function of Relationship With the Comparison Target

\begin{tabular}{|c|c|c|c|c|c|c|}
\hline & \multicolumn{6}{|c|}{ Comparison Target } \\
\hline & \multicolumn{2}{|c|}{ Disliked } & \multicolumn{2}{|c|}{ Rival } & \multicolumn{2}{|c|}{ Close } \\
\hline & $\gamma_{10}$ & $S E$ & $\gamma_{10}$ & $S E$ & $\gamma_{10}$ & $S E$ \\
\hline \multicolumn{7}{|l|}{ Ability ranking } \\
\hline Target & $-0.26^{*}$ & .03 & 0.00 & .02 & $0.10^{*}$ & .03 \\
\hline Self & -0.05 & .03 & $0.21^{*}$ & .02 & -0.02 & .03 \\
\hline Target - self & $-0.16^{*}$ & .03 & $-0.25^{*}$ & .03 & $0.09^{*}$ & .03 \\
\hline
\end{tabular}

Note. Standardized coefficients. Coefficients with an asterisk are significant at $p<.01$. target, the self, and their difference (i.e., the target's ability minus self's ability). In support of $\mathrm{H} 2$ and $\mathrm{H} 3$, the difference between the target and the self was negatively associated with both dislike and rivalry. In $18.9 \%$ of the comparisons the comparers ranked their own ability as superior to that of the person who had outperformed them, and these instances were associated with more dislike $(\gamma=0.44, \quad S E=0.09)$ and rivalry $(\gamma=0.23$, $S E=0.06)$ toward the target $(p s<.001)$.

Although dislike and rivalry both had the effect of reducing the perceived differences in the abilities of self and the target, analyzing the ratings of the target and the self separately showed that dislike and rivalry exerted their effects in different ways. Dislike predicted ascribing the target lower ability levels, whereas rivalry predicted ascribing the self higher ability levels. In other words, it appears that dislike made comparers more reluctant to endow the target with high abilities, whereas rivalry made comparers more eager to confer high abilities to the self. Because rivalry predicted dislike $(\gamma=0.17, S E=0.04)$, I also conducted the preceding analyses again, entering rivalry and dislike simultaneously; doing so did not alter the results.

Table 2 also shows that the closer the target, the more the target was described as capable and as more capable than the self. Closeness did not predict rivalry $(\gamma=$ $-0.04, S E=0.03)$ but did predict dislike $(\gamma=-0.55$, $S E=0.03, \quad p<.001)$. Therefore, I conducted the preceding analyses again, entering closeness and dislike simultaneously; doing so did not alter the effects of dislike but did eliminate the effects of closeness (all $|\gamma| \mathrm{s} \leq 0.07$, SEs $=0.04, n s)$.

I also tested the quadratic effects of closeness on ability rankings (while controlling for the linear effects of closeness). The quadratic component did not predict ratings of the target's abilities $(\gamma=0.00, S E=0.03)$ but did predict ratings of the self's abilities $(\gamma=-0.12$, $S E=0.03, p<.001)$, and - as predicted by $\mathrm{H} 1$ - the difference between ratings of the target and the self $(\gamma=0.10, S E=0.03, p<.01)$. Controlling for the linear and quadratic effects of dislike did not alter these results. Figure 1 shows the mean ability ratings for self and target at each level of closeness and shows that ratings of the self's abilities are at their maximum - and self-other differences are at their minimum - at moderate levels of closeness.

Effect of target abilities on feelings. To test the effects of perceived target ability on emotional reactions to the other's superior performance, I again used the model in Equation 1 but with overall feelings as the outcome and ratings of target ability as the predictor. Because target dislike was associated with more negative emotional reactions $(\gamma=0.48, S E=0.03, p<.001)$, I controlled for the effect of target dislike. In accord with 


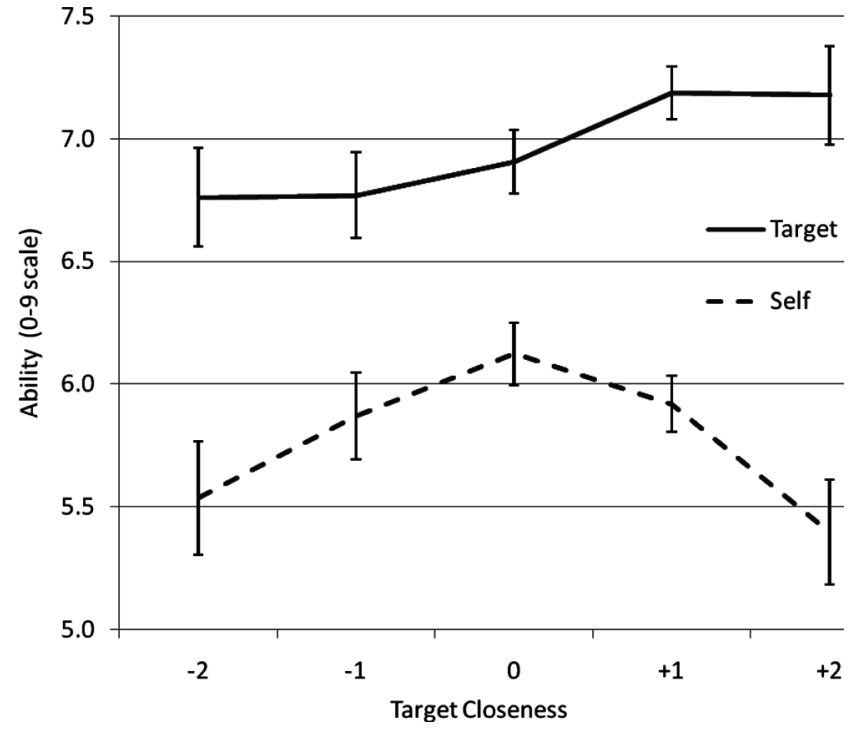

FIGURE 1 Mean ratings (and standard errors) of the abilities of self and target in the comparison domain as a function of target closeness.

$\mathrm{H} 5$, the greater the abilities ascribed to the target, the more positively participants felt about being outperformed $(\gamma=0.24, S E=0.03, p<.001)$.

Gender. Finally, to test if gender predicted variance in the outcomes and slopes just assessed, I expanded Equation 2 as follows:

$$
\mathrm{Y}_{\mathrm{ij}}=\gamma_{00}+\gamma_{01} \mathrm{G}_{\mathrm{j}}+\mathrm{u}_{0 \mathrm{j}}+\gamma_{10} \mathrm{X}_{\mathrm{ij}}+\gamma_{11} \mathrm{G}_{\mathrm{j}} \mathrm{X}_{\mathrm{ij}}+\mathrm{u}_{\mathrm{jj}} \mathrm{X}_{\mathrm{ij}}+r_{\mathrm{ij}},
$$

where $\mathrm{G}_{\mathrm{j}}$ is $j$ 's gender (dummy-coded female $=0$, male $=1)$, and $\gamma_{01}$ and $\gamma_{11}$ are the effects of gender on outcomes and slopes, respectively. Only two effects were significant: Male participants reported more dislike of and rivalry with the target $(\gamma \mathrm{s}=0.20$ and 0.30 , $S E=0.09$ and $0.11, p \mathrm{~s}<.05)$.

\section{STUDY 2}

Study 2 differed from Study 1 in the following ways. First, each respondent described only one comparison; specifically, undergraduate respondents described the last time another undergraduate they knew had academically outperformed them. I limited the targets to known others because I wanted to assess how comparers felt about the target prior to the comparison. I limited the domain to academics in order to minimize the error variance introduced by variability in the type of attribute being compared (e.g., strength vs. popularity); I chose academics because most previous upward comparison studies have focused on academic or intellectual performance, and Study 1 confirmed that undergraduate frequently make comparisons related to academics. Second, respondents ranked their own ability and the target's ability as percentile ranks relative to other undergraduates; thus, the ability ratings had an identifiable meaning. Third, to test the hypothesis that people would be less likely to elevate a target above the self if they were concerned about their standing relative to that particular target, I assessed the degree to which respondents personalized the comparison. Finally, rather than assess overall feelings about the target's performance, I assessed specific emotional reactions, such as envy and confidence.

\section{Method}

Participants. University of Idaho undergraduates (361 female, 184 male, 8 unknown; age range $=18-57$ years, $M=21.9, S D=6.5$ ) participated for extra credit in psychology classes. The participants described their ethnicity as follows: $85.7 \%$ European American; 5.1\% Latino; 4.0\% Asian American, Native American, or African American; and 5.1\% "Other."

Materials and procedure. Participants completed an online questionnaire. After responding to some other questions irrelevant to the current study, participants were asked to describe "the last time you found out you were academically outperformed by another student who you know (not a stranger)." Next they were asked to estimate the percentile ranks of their own and the other student's abilities "in this performance domain compared to other students at this university" on 11-point scales ranging from 0 th percentile (the worst) to 100th percentile (the best). All intermediate points were clearly labeled (e.g., 30th percentile (worse than 70\%), 50th percentile (in the middle), and 70th percentile (better than $70 \%)$ ). The remaining 10 questions were answered on 0 (not at all) to 9 (very much) scales. One assessed personalization: "How much do you care about how your performance compares with the performance of this other student in particular?" Five assessed emotional reactions, specifically, to what extent "did learning about this other student's performance make you feel... envious, ... sad, ... ashamed, ... angry, ... confident that I could do better in the future?" The final four items assessed feelings about the target. Specifically, participants were asked, "During the time you've known this person, not focusing on this particular event, to what extent have you felt... dislike,... liking $[R], \ldots$ annoyance/irritation, ... affection/warmth [R]." I averaged these four items to create an overall index of target dislike $(\alpha=.62)$. 
TABLE 3

Descriptive Statistics (Study 2)

\begin{tabular}{lcc}
\hline Measure & $M$ & $S E$ \\
\hline Percentile rankings & & \\
$\quad$ Target's ability & 74.0 & 0.73 \\
$\quad$ Own ability & 69.1 & 0.75 \\
Other ratings & & \\
$\quad$ Dislike & 3.04 & 0.08 \\
Personalization & 5.89 & 0.13 \\
Envious & 5.46 & 0.13 \\
Ashamed & 4.02 & 0.13 \\
Sad & 3.96 & 0.13 \\
Angry & 3.67 & 0.13 \\
Confident & 7.05 & 0.12 \\
\hline
\end{tabular}

Note. Percentile rankings were from 0 to 100 . Other ratings were on 0 -to-9 scales.

\section{Results and Discussion}

Descriptive statistics. Table 3 shows the descriptive statistics for the study variables. The percentile ranking of the target's abilities exceeded that of the self's abilities, $t(552)=6.2, p<.001$, and both the self and target were ascribed percentile ranks far above average (i.e., $50), t(552) \mathrm{s}>25, p \mathrm{~s}<.001$. Indeed, in accord with the "better than average effect," $75.8 \%$ of participants rated their abilities in this domain in which they were outperformed as better than that of the average undergraduate at their university, whereas only $6.5 \%$ rated their abilities as below average. As in Study 1, people were more likely to like than dislike the target. They also tended to feel envious of the target yet quite confident that they could do better in the future. The two interpersonal predictors, dislike and personalization, were unrelated, $r(551)=-.06$.

Effects of dislike on ability rankings. In the remaining analyses, I standardized the predictor variables and report standardized regression coefficients. In accord with $\mathrm{H} 2$, dislike of the target predicted a smaller difference between ratings of the target's ability and the self's ability $(\beta=-.15, S E=.04, p<.001)$. In $20.6 \%$ of the comparisons the comparers ranked their own ability as superior to that of the person who had outperformed them; dislike of the target was greater among people who ranked their own ability as superior $(M=3.8$, $S E=0.21)$ than among people who did not $(M=2.9$, $S E=0.09), t(551)=4.6, p<.001$. Separate analyses of self and target ratings showed that dislike predicted lower ratings of the target's ability $(\beta=-.21, S E=.04$, $p<.001)$ but did not predict ratings of one's own ability $(\beta=-.05, S E=.04)$. Figure 2 clarifies the implications of dislike for the "genius effect" by juxtaposing the rankings of self and target when dislike of the target is high or low: Dislike reduced the ability ascribed to the

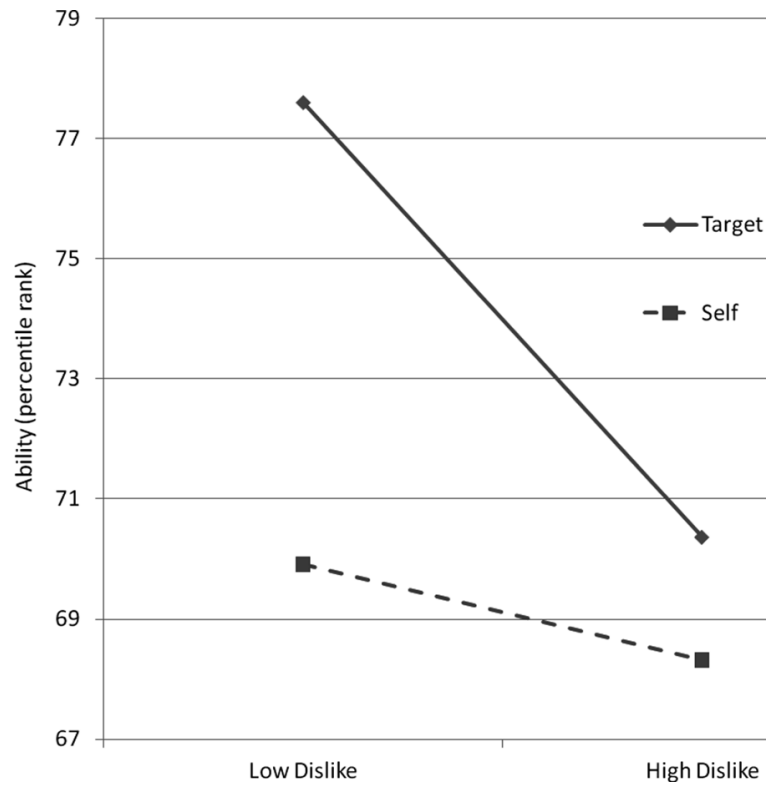

FIGURE 2 Predicted ratings of the abilities of self and target at 1 standard deviation above and below the mean of target dislike.

target and thus the perceived difference in the abilities of the self and the target.

Effects of personalizing on ability rankings. In accord with $\mathrm{H} 4$, personalizing was significantly greater among people who ranked their own ability as superior to that of the target $(M=6.6, S E=0.28)$ than among people who did not $(M=5.7, S E=0.14), t(551)=4.7$, $p<.01$. Likewise, personalizing predicted a marginally smaller difference between ratings of the target's ability and the self's ability ( $\beta=-0.07, S E=.04, p<.1)$. When analyzing the self and target ratings separately, the effects of personalizing were in the expected directions but were not statistically significant $(\beta \mathrm{s}=-0.05$ and $0.03, S E \mathrm{~s}=.04)$.

I also tested if personalization moderated the effects of dislike on target ability by regressing the Personalization $\times$ Dislike interaction on target ability (controlling for the main effects); the interaction effect was significant, $\beta=.10, S E=.04, s r^{2}=.01, p=.01$. Figure 3 shows that people who both dislike the target and care how they compare with that target are particularly unlikely to ascribe high abilities on the target. (The Personalization $\times$ Dislike interaction did not predict ratings of one's own abilities, $\beta=-0.02, S E=.04$.)

Effect of target abilities on feelings. Next, I regressed each type of emotion (anger, envy, shame, sadness, and confidence) onto ratings of target ability. (Not surprisingly, target dislike predicted negative feelings. Specifically, dislike predicted more shame, envy, sadness, and anger; $r \mathrm{~s}=-.08,-.09,-.13$, and -.30 , 


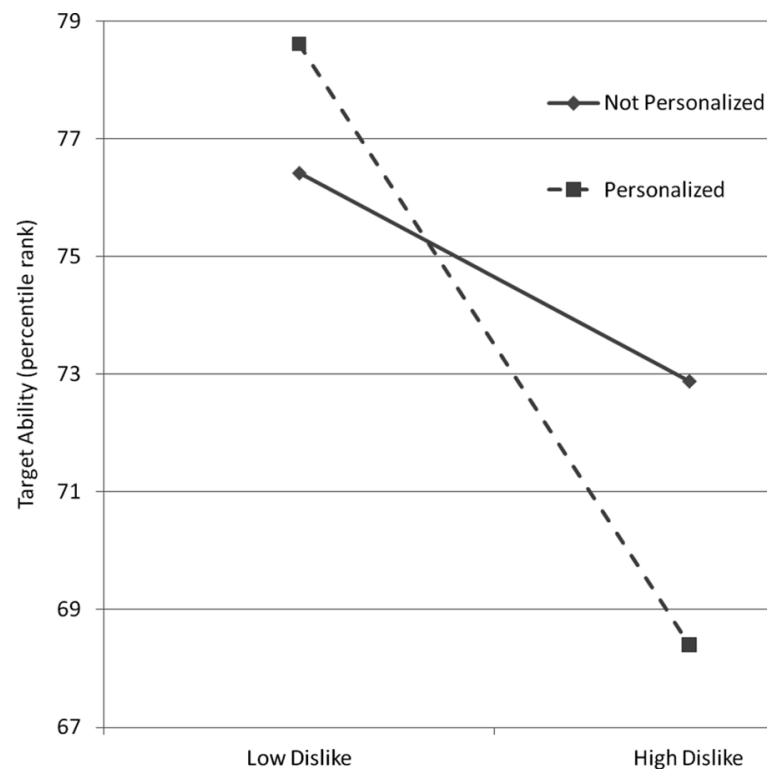

FIGURE 3 Predicted ratings of target ability as a function of target dislike and personalization (shown at 1 standard deviation above and below the mean of the predictor variables).

respectively; $p \mathrm{~s} \leq .05$. Therefore, in each regression $\mathrm{I}$ controlled for the effect of target dislike.) In accord with $\mathrm{H} 5$, ascribing greater abilities to the target predicted feeling less angry, ashamed, and sad $(\beta \mathrm{s}=-0.13$, -0.15 , and $-0.18, S E \mathrm{~s}=0.04, p \mathrm{~s}<.01)$. On the other hand, ascribing greater abilities to the target also predicted feeling less confident $(\beta=-0.10, S E=0.04$, $p<.05)$. Target abilities were unrelated to envy $(\beta=0.03, S E=0.04)$.

Gender. I tested the effects of gender (including the two-way interactions of gender with ability rankings, dislike, and personalization) on all possible outcomes. (I did not test three-way interactions.) Only two effects were significant: Male participants reported liking the target less and feeling less sad about the target's performance $(\beta \mathrm{s}=0.10$ and $-0.09, S E \mathrm{~s}=.04, p \mathrm{~s}<.05)$.

\section{GENERAL DISCUSSION}

Using somewhat different methods, two studies examined naturally occurring experiences of being outperformed. Not surprisingly, after a target outperformed them, people typically ranked the abilities of the target in that domain as exceeding their own. Nonetheless, in keeping with the "better than average effect" (Alicke \& Govorun, 2005), people still tended to rate their own abilities as above average. Moreover, as predicted, interpersonal factors-closeness, dislike, rivalry, and personalization-moderated people's rankings.
In support of $\mathrm{H} 1$, people reported relatively small differences in perceived abilities between the self and moderately close targets (such as ordinary friends and coworkers), presumably because inferiority to moderately close others is more upsetting than inferiority to either strangers (who hold little personal significance) or extremely close others (who overlap with your own identity; McFarland et al., 2001; Pinkus et al., 2008; Tesser, 1988). Of interest, what narrowed the gap between the abilities of the self and moderately close targets were not low ratings of the target but high ratings of the self. The effects of closeness on self-ratings and target ratings were distinct processes: Whereas the effect of closeness on self-ratings was curvilinear and was unaffected by liking, the effect of closeness on target ratings was linear, positive, and mediated by liking for the target. Consequently, the greatest divergence in perceived abilities was between the self and an extremely close other (such as a long-term romantic partner). Such a pattern is consistent with the extended SEM model: Perceiving oneself and one's partner as having complementary abilities allows one to bask in the reflected glory of an extremely capable partner while avoiding negative feelings (such as jealousy or competitiveness) that might undermine feelings of closeness and solidarity (Beach et al., 1998).

My second hypothesis was that the less people liked an upward comparison target, the less likely they would be to ascribe high ability levels to that target. The rationale for this hypothesis was simple - people prefer to ascribe positive attributes to liked others and negative attributes to disliked others (Heider, 1958) - and the support for this hypothesis was clear and robust. Moreover, because disliking the target did not affect the perceived abilities of the self, disliked targets ended up being rated as similar or even inferior to the merely "above average" self. In short, dislike dulled the "genius effect".

H3 stated that a competition or rivalry with the target also would narrow the perceived differences between the abilities of the self and the target. The results also clearly supported this hypothesis. The stronger their rivalry with the target, the more people described themselves as capable and thus as similar to the highly capable target. In sum, dislike and rivalry both narrow the gap between the self and the target, but they do so in distinct ways: Dislike lowers target ratings, whereas rivalry raises self-ratings.

Judging an upward target to be unusually gifted may help protect positive beliefs about how your abilities compare with those of the average person but will not protect positive beliefs about how your abilities compare with those of that specific target who just outperformed you. Therefore, $\mathrm{H} 4$ posited that when comparers personalize an upward comparison, they will minimize the 
discrepancy between their abilities and those of the upward target. The data offered weak support for H4. Specifically, people who personalized the comparison showed a marginal tendency to lessen the perceived superiority of the target to the self and a significant tendency to assert that their abilities actually exceeded those of the target. The effect of personalizing was weak in part because it was moderated by target liking; specifically, personalizing the comparison predicted lower ratings of the target only if the target was disliked. In other words, personalizing intensified the negative impact of dislike on target ratings: Comparers were especially loath to elevate a person's abilities if they both disliked that person and cared about their standing relative to that person.

Finally, in accord with $\mathrm{H} 5$, the results found that believing the target to be especially capable was associated with feeling less upset about the target's superior performance. On the other hand, believing the target to be especially capable did not reduce feelings of envy and predicted feeling less confident about being able to do better next time (at least relative to the person who outperformed you). Such results suggest that the genius effect may be more effective at assuaging hurt and protecting self-esteem in the moment than at inspiring hope for future success.

\section{Limitations}

Studying naturally occurring social comparisons has both advantages and disadvantages. An advantage is increased confidence that the findings will apply to everyday life. A disadvantage is the loss of experimental control. Because of the lack of experimental control, the current results can be explained by different causal models. For example, rivalry may predict describing oneself as capable because rivalry causes people to assert that their abilities "rival" those of the target, or because believing one's abilities rival those of the target causes people to consider that target as a rival, or both. Experimental manipulations (e.g., manipulating rivalry or ability beliefs in a laboratory study) would provide clearer tests of these alternative causal models. Laboratory studies also enable control of innumerable other variables (e.g., the exact standing of the comparer and the target) that I could not control in the current research.

Another limitation is that my measure of personalization ("How much do you care about how your performance compares with the performance of this other student in particular") may reflect a mixture of how much respondents care about their standing relative to the particular target and how much they care about their performance or standing more generally. Nonetheless, this item was likely measuring personalization to some extent because it predicted how strongly people derogated the ability of a disliked target - which is a sensible consequence of caring about one's standing relative to that target, but not of caring about one's performance or status more generally. A final limitation is that the participants were American undergraduates and additional research is needed to be confident that the results will generalize to other populations.

\section{Conclusions and Implications}

Construing people who outperform us as unusually gifted is an appealing way to transform a potentially awkward comparison into a "win-win" situation in which both the self and the other can be viewed as capable. In the real world, though, our relationship with the other person limits our willingness to use this explanation. Whereas we are relatively generous in bestowing high levels of ability on very close and liked others, we are stingier in conferring such compliments on distant and disliked others, especially when our standing relative to a disliked other is personally important to us. We also are reluctant to admit that the self is less capable than those with whom we have an ongoing competition or an ongoing relationship that is only moderately close. More broadly, the current findings help to remind us that any type of social cognition that involves making judgments about others (or the self in relation to others) is likely to be shaped by one's preexisting relationship with and feelings about those other people.

Although upward comparisons can evoke envy, self-doubt, and dejection, they also can strengthen inspiration, confidence, and determination (Collins, 1996), and even facilitate success in endeavors ranging from academic performance to smoking cessation (e.g., Blanton et al., 1999; Gerrard, Gibbons, Lane, \& Stock, 2005). The emotional, motivational, behavioral, and self-evaluative consequences of upward comparisons depend in part on the judgments people make regarding the abilities of the self and the upward target. For example, the "proxy model" of ability comparisons (Wheeler, Martin, \& Suls, 1997) describes how people are more likely to undertake an unfamiliar challenge if they judge their abilities to match those of a target who has successfully met that challenge. Likewise, decades of research on modeling as a means of facilitating positive behavior change has found that the most effective models are those that people perceive to be successful in the relevant behavioral domain but also similar to the self in ways that promise that the self can be similarly successful (Bandura, 1986).

In sum, we are more likely to be encouraged by upward comparisons if we conclude that our abilities are similar to those of an admirable target and therefore we too can enjoy similar levels of accomplishment. The current research suggests that we may be particularly 
likely to conceptualize the self and the target in that way if the upward target is a moderately close, liked other with whom we have an ongoing competition; conversely, we may be less likely to be motivated by upward targets who are extremely close, or highly disliked, or simply unimportant to us. For example, by exaggerating the gulf between our abilities and those of extremely close others, we may render their achievements less personally threatening but at the same time also less personally motivating. The current research focused on how relationship factors moderate ability judgments and not on the myriad other consequences of social comparisons. Therefore, to test the preceding speculations, further research is needed on how interpersonal factors-by shaping our experience of social comparisons-shape the emotional, motivational, and behavioral consequences of the comparisons we make in the course of our daily lives.

\section{ACKNOWLEDGMENTS}

I am grateful to Kyoung-Deok Baik for helping me with coding and data entry.

\section{REFERENCES}

Alicke, M. D., \& Govorun, O. (2005). The better-than-average effect. In M. D. Alicke, D. A. Dunning, \& J. I. Krueger (Eds.), Studies in self and identity (pp. 85-106). New York: Psychology Press.

Alicke, M. D., LoSchiavo, F. M., Zerbst, J., \& Zhang, S. (1997). The person who outperforms me is a genius: Maintaining perceived competence in upward social comparison. Journal of Personality and Social Psychology, 73, 781-789.

Bandura, A. (1986). Social foundations of thought and action: A social cognitive theory. Englewood Cliffs, NJ: Prentice-Hall.

Beach, S., \& Tesser, A. (1993). Decision making power and marital satisfaction: A self-evaluation maintenance perspective. Journal of Social and Clinical Psychology, 12, 471-494.

Beach, S., Tesser, A., Fincham, F. D., Jones, D. J., Johnson, D., \& Whitaker, D. J. (1998). Pleasure and pain in doing well, together: An investigation of performance-related affect in close relationships. Journal of Personality and Social Psychology, 74, 923-938.

Blanton, H., Buunk, B. P., Gibbons, F. X., \& Kuyper, H. (1999). When better-than-others compares upward: The independent effects of comparison choice and comparative evaluation on academic performance. Journal of Personality and Social Psychology, 76, 420-430.

Brickman, P., \& Bulman, R. J. (1977). Pleasure and pain in social comparison. In J. M. Suls \& R. L. Miller (Eds.), Social comparison processes: Theoretical and empirical perspectives (pp. 149-186). Washington, DC: Hemisphere.

Collins, R. L. (1996). For better or worse: The impact of upward social comparison on self-evaluations. Psychological Bulletin, 119, 51-69.

Dijksterhuis, A., Spears, R., Postmes, T., Stapel, D., Koomen, W., Knippenberg, A. V., et al. (1998). Seeing one thing and doing another: Contrast effects in automatic behavior. Journal of Personality and Social Psychology, 75, 862-871.
Gerrard, M., Gibbons, F. X., Lane, D. J., \& Stock, M. L. (2005). Social comparison and smoking cessation: Comparison level predicts success. Health Psychology, 24, 623-629.

Heider, F. (1958). The psychology of interpersonal relations. New York: Wiley.

Huguet, P., Dumas, F., Monteil, J., \& Genestoux, N. (2001). Social comparison choices in the classroom: Further evidence for students' upward comparison tendency and its beneficial impact on performance. European Journal of Social Psychology, 31, 557-578.

Landis, J. R., \& Koch, G. G. (1977). The measurement of observer agreement for categorical data. Biometrics, 33, 159-174.

Lassiter, G. D., Clark, J. K., Munhall, P. J., \& Lindberg, M. J. (2008). And I thought I was bad! The idiot effect in social judgment. Social Cognition, 26, 347-356.

Lassiter, G. D., \& Munhall, P. J. (2001). The genius effect: Evidence for a nonmotivational interpretation. Journal of Experimental Social Psychology, 37, 349-355.

Locke, K. D. (2003). Status and solidarity in social comparison: Agentic and communal values and vertical and horizontal directions. Journal of Personality and Social Psychology, 84, 619-631.

Locke, K. D. (2007). Personalized and generalized comparisons: Causes and consequences of variations in the focus of social comparisons. Personality and Social Psychology Bulletin, 33, 213-225.

Locke, K. D., \& Nekich, J. (2000). Agency and communion in naturalistic social comparison. Personality and Social Psychology Bulletin, 26, 864-874.

Lockwood, P., \& Kunda, Z. (1997). Superstars and me: Predicting the impact of role models on the self. Journal of Personality and Social Psychology, 73, 91-103.

Luke, D. A. (2004). Multilevel modeling (Sage University Paper Series on Quantitative Applications in the Social Sciences, Series No. 07-143). Newbury Park, CA: Sage.

McFarland, C., Buehler, R., \& MacKay, L. (2001). Affective responses to social comparisons with extremely close others. Social Cognition, 19, 547-586.

Mussweiler, T., Ruter, K., \& Epstude, K. (2004). The ups and downs of social comparison: Mechanisms of assimilation and contrast. Journal of Personality and Social Psychology, 87, 832-844.

Osgood, C. E. (1960). Cognitive dynamics in the conduct of human affairs. Public Opinion Quarterly, 24, 341-365.

Pinkus, R. T., Lockwood, P., Schimmack, U., \& Fournier, M. (2008). For better and for worse: Social comparisons in romantic relationships. Journal of Personality and Social Psychology, 95, 1180-1201.

Seaton, M., Marsh, H. W., Dumas, F., Huguet, P., Monteil, J. M., Regner, I., et al. (2008). In search of the big fish: Investigating the coexistence of the big-fish-little-pond effect with the positive effects of upward comparison. British Journal of Social Psychology, 47, 73-103.

Seta, J. J. (1982). The impact of comparison processes on coactors' task performance. Journal of Personality and Social Psychology, $42,281-291$.

Seta, J. J., Seta, C. E., \& Donaldson, S. (1991). The impact of comparison processes on coactors' frustration and willingness to expend effort. Personality and Social Psychology Bulletin, 17, $560-568$.

Tesser, A. (1988). Toward a self-evaluation maintenance model of social behavior. In L. Berkowitz (Ed.), Advances in experimental social psychology (Vol. 21, pp. 181-222). San Diego, CA: Academic Press.

Wheeler, L., Martin, R., \& Suls, J. (1997). The proxy model of social comparison for self-assessment of ability. Personality and Social Psychology Review, 1, 54-61.

Wheeler, L., \& Miyake, K. (1992). Social comparison in everyday life. Journal of Personality and Social Psychology, 62, 760-773. 